\title{
COERÊNCIA MICRO E MACROESTRUTURAL NO DISCURSO POLÍTICO DE DILMA ROUSSEFF
}

Alessandra Alves de Carvalho NOGARE ${ }^{1}$

Jocyare SOUZA ${ }^{2}$

\author{
${ }^{1}$ Mestre em Letras pela Universidade Vale do Rio Verde (UninCor). E-mail: alessanogare25@ hotmail.com \\ ${ }^{2}$ Doutora em Linguística pela UNICAMP. Docente da Universidade Vale do Rio Verde (UninCor). \\ E-mail: prof.jocyare.souza@unincor.edu.br
}

Recebido em: 08/05/2015 - Aprovado em: 13/07/2015 - Disponibilizado em: 15/07/2014

Resumo: Política não se faz somente com palavras, mas é no discurso que se instaura o poder de persuasão que faz o dominador ocupar seu lugar político. É por meio do discurso que se mostram as ideias e os ideais nos quais se acreditam. O preparo prévio do discurso, principalmente o político, é fundamental.O presente artigo se incube, portanto, de evidenciarcomo um discurso mal elaborado pode enfraquecer a imagem de um político, no caso, o discurso da presidenta Dilma Rousseff na $7^{\mathrm{a}}$ cúpula Brasil - União Europeia em Bruxelas. O objetivo deste é analisar trechos que comprovem como a falta de coerência e coesão pode prejudicar o êxito do discurso e arranhar a imagem de um político. Faremos uso do arcabouço teórico da Linguística Textual (KOCH, 1997, 2004), estabelecendo um diálogo com (CHARAUDEAU, 2013) para tentarmos comprovar nossa hipótese, ou seja, a falta de coerência e coesão no discurso da presidenta. Uma frase mal formulada, uma palavra mal colocada pode levar o político ao descrédito. A coerência e a coesão são de suma importância para o êxito do discurso, ou seja, para que os interlocutores se entendam e compartilhem ideias. Em se tratando de um evento internacional, o cuidado deve ser redobrado, já que o mesmo foi coberto por toda mídia e por isso teve tanta repercussão.

Palavras-Chave: Discurso Político. Coesão e Coerência. Linguística Textual.

\section{MICRO AND MACRO-STRUCTURAL COHERENCE ISSUES IN DILMA ROUSSEFF'S POLITICAL SPEECH}

\begin{abstract}
Politics is not made only with words but it's in the speech that we establish the power of persuasion that makes the dominator be in his/her political place. It's through the speech that we show our ideias and ideals in which we believe. The previous prepare of the speech, especially the political, is very important. The previous prepare of the speech, especially the political, is very important. The present article aims to show how a bad- planned speech may contribute to harm the image of a politician, in this case, the speech of presidentDilmaRousseff in the $7^{\text {th }}$ BrazilEuropean Union Summit in Brussels. This aims to analyze pieces that prove how the lack of cohesion and coherence may affect the success of a speech and weak the image of a politician. We have chosen the Textual Linguistics (KOCH, 1997, 2004)to sustain us theoretically, establishing a dialog with (CHARAUDEAU, 2013) to try to prove our hypotheses, i.e., the lack of cohesion and cohere A bad-planned sentence, a word in the wrong place may take the politician to discredit. The coherence and cohesion are very important to the success of the speech, in other words, in order to make the interlocutors understand each other and share ideas. In terms of an international event, the care needs to be bigger, since that it was covered by all kinds of media and just because of it has had so much repercussion.nce in the speech of president.
\end{abstract}

Keywords: PoliticalSpeech. Cohesion and Coherence.Textual Linguistics.

\section{Considerações Iniciais}

Começaremos este artigo apresentando nosso arcabouço teórico, a Linguística Textual. Esta tem por interesse, estudar o texto, seu funcionamento, bem como os processos e as estratégias de sua construção, visto que um texto não é um amontoado de palavras e/ou frases isoladas, mas, sim, uma unidade linguística com propriedades específicas. A Linguística Textual começou a surgir como ciência na Europa, especialmente na Alemanha, na década de 60 e divide-se em três momentos: o primeiro foi o da análise 
transfrástica, a qual parte da frase para o texto. Segundo Bentes (2012, p. 247), a análise transfrástica tenta explicar "fenômenos que não conseguiam ser explicados pelas teorias sintáticas e/ou pelas teorias semânticas que ficassem limitadas ao nível da frase"; em segundo, a construção das gramáticas textuais, que descreviam a competência textual do falante e, em terceiro, Bentes (2012, p. 247) diz que:

O texto passa a ser estudado dentro de seu contexto de produção e a ser compreendido não como um produto acabado, mas como um processo, resultado de operações comunicativas e processos linguísticos em situações sociocomunicativas, parte-se, assim, para a elaboração de uma teoria do texto.

Como podemos perceber, o texto vai além das palavras. É preciso analisar o contexto em que essas palavras estão inseridas e se $o$ interlocutor tem conhecimento de seu significado, caso contrário, não haverá sentido para quem recebe a mensagem.

Ainda para Bentes (2012, p. 249),

O texto é a unidade linguística mais elevada, a partir da qual seria possível chegar, por meio de segmentação, a unidades menores a serem classificadas. A segmentação e a classificação de um texto em unidades menores deveriam, no entanto, sempre considerar a função textual dos elementos individuais, ou seja, que tipo de papel cada elemento desempenha em uma dada configuração textual.
Para que unidades menores (palavras) construam um texto, é necessário que se faça uso da coesão e coerência, elementos que não podem faltar para que um texto tenha sentido. Para Fávero (2012, p. 31), “a coesão e a coerência constituem fatores básicos de textualidade". Numa conversa, os interlocutores precisam se entender para que haja êxito no discurso, ou seja, que ambos se compreendam. O excesso de interrupção de ideias, isto é, ideias não terminadas, excesso de explicações talvez não tão necessárias pode contribuir para um não entendimento do interlocutor. Ainda para Fávero (2012, p. 31),

A coesão revela-se, às vezes, por meio de marcas formais na estrutura linguística, manifestando-se na organização sequencial do texto, sendo percebida na superfície textual em seus aspectos léxico, sintático e semântico; outras vezes, vem subentendida, não marcada linguisticamente.

A coesão é fator básico para que haja coerência. Sem a primeira, o interlocutor pode não entender a mensagem que o locutor quer passar. Para Koch (1997, p. 41), a coerência "diz respeito ao modo como os elementos subjacentes à superfície textual vêm a constituir, na mente dos interlocutores, uma configuração veiculadora de sentidos." A autora quer dizer que cada elemento, ou seja, cada palavra precisa estar interligada dentro de um contexto para que haja sentido.

Koch e Travaglia (apud BENTES, 2012, p. 257) consideram ainda que "a 
textualidade ou a textura é aquilo que faz de uma sequência linguística um texto e não um amontoado de palavras. A sequência é percebida como texto quando aquele que recebe é capaz de percebê-la como uma unidade significativa global". Isso é coerência: o entrelaçamento de palavras que ao se ligarem produzem sentido, ou seja, um significado global. Mas para que isso aconteça, é preciso que vários elementos textuais estejam presentes na produção textual, como a referência ou referenciação, por exemplo. Referenciação é o processo de construção e reconstrução dos objetos do discurso, isto é, objetos representados a partir de conhecimentos compartilhados socialmente. É, portanto, designada como um processo em que o sujeito faz opções visando um querer-dizer. De acordo com Koch (2004, p. 61),

\begin{abstract}
A referenciação constitui (...) uma atividade discursiva. O sujeito, por ocasião da interação verbal, opera sobre o material linguístico que tem a sua disposição, operando escolhas significativas para representar estados de coisas, com vistas à concretização de sua proposta de sentido.
\end{abstract}

O sujeito instaura seu discurso a partir de um lugar, de um momento e para demonstrar isso, ele precisa fazer uso de pronomes ou advérbios que se refiram ao objeto sobre o qual ele fala. Por exemplo: Maria saiu. Ela ${ }^{\mathbf{1}}$ não irá demorar. Para não

${ }^{1}$ Grifo nosso. Todas as palavras em negrito deste artigo foram destacadas para chamar a atenção do leitor. precisar repetir o nome Maria, faz-se uso do pronome pessoal ela para se referir à Maria.

Uso de pronomes pessoais e advérbios como referentes é muito importante em nosso idioma. É o caso do uso de advérbios como aqui e ali quetambém situam o local em que está o locutor, que pode estar perto ou longe do objeto de que se fala. Dentro da referenciação, temos também a anáfora e a catáfora, que no caso desta última, consiste em anunciar algo que ainda será dito. Por exemplo: Paulo vivia ali, numa vila muito simples e esquecida. Percebe-se que o advérbio ali evidencia que o local ainda será anunciado pelo locutor. Uma referenciação mal empregada pode prejudicar o sentido do texto e causar confusão no entendimento do interlocutor sobre a qual item do discurso o locutor se refere. Para Fávero (apud FÁVERO, ANDRADE, AQUINO, 2000 p. 32), "a coesão referencial pode contribuir para o entendimento do tópico abordado pelo locutor, principalmente quando se trata da reiteração do mesmo item lexical. A alta incidência de repetições de um mesmo termo pode contribuir para a coesão textual", mas o excesso de referenciação também pode prejudicar a clareza do texto, que é o que veremos logo a seguir. Quebra de ideias, orações subordinadas mal empregadas, uso de apostos desnecessários são outros itens que também podem prejudicar o entendimento de um texto oral ou escrito.

Alguns gêneros textuais orais lembram a escrita, como é o caso de um discurso 
oficial, por exemplo. Esse tipo de discurso é elaborado previamente, com todo cuidado para preservar a imagem do político em questão. É escrito para que seja lido no momento propício para um grande número de pessoas e pode ser veiculado pela mídia. Muitas das vezes, simula um discurso oral, ou seja, a forma como é escrito nos dá a impressão de que o locutor fala naturalmente conosco, como é o caso do jornal televisivo. Ao tratarmos de um discurso oral, não podemos esquecer que ele pode apresentar recursos próprios da fala como repetições, truncamentos, autocorreções ou estratégias modalizadoras.

A repetição pode colaborar para o êxito do discurso ou comprometer o entendimento do interlocutor, quando esta é feita de forma inapropriada, causandoconfusão e ambiguidade no discurso; já o truncamento é usado quando o locutor percebe que a ideia não fará sentido ou colocará a sua imagem em risco. Portanto, o locutor interrompe a palavra ou frase antes de ser completada e realiza a autocorreção, ou seja, o próprio locutor se corrige para não deixar que o interlocutor o faça.

Segundo Koch (2004, p. 122), “As correções decorrem da necessidade de $\mathrm{o}$ locutor solucionar, imediatamente, após ou mesmo durante a materialização de um segmento, dificuldades nesse detectadas por ele mesmo ou pelos parceiros, podendo, pois, ser auto/heterocondicionadas." Autocorreções são também chamadas de estratégias modalizadoras. De acordo com (KOCH, 2004, p. 125), “Estratégias modalizadoras ou metapragmáticas são aquelas que têm por objetivo preservar a face do locutor, por meio da introdução no texto de atenuações, ressalvas (...).”Fazemos isso o tempo todo, a fim de que preservemos nossa face e não deixemos que o outro nos corrija.

Nosso aporte teórico nos possibilitará tratar, por meio de seus elementos de análise, problemas que evidenciam a falta de coerência/coesão nos fragmentos explicitados em nosso corpus, trechos do discurso de Dilma na $7^{\mathrm{a}}$ Cúpula Brasil - União Europeia em 24 de fevereiro de 2014.

\section{Retextualização: a multimodalidade enquanto recurso de coerência ecoesão}

Um texto pode ser oral ou escrito e é necessário se ater às especificidades de cada um, já que o texto escrito é planejado e replanejado de acordo com a necessidade, podendo ser apagado e recomeçado sempre que preciso. Já o texto falado, pode ser planejado ou não. Segundo Rodrigues (2003, p. 20), “em termos mais gerais, a língua falada apresenta uma tendência para o não planejado", ou seja, a conversa entre dois ou mais interlocutores precisa ter um tema (o que é planejado), mas seu desenvolvimento pode variar, de acordo com a necessidade. Ainda para Rodrigues (2003, p. 20), "planejamento e realização do discurso coincidem no eixo temporal, ou são praticamente 
concomitantes", isto é, o planejamento é feito à medida que o tópico discursivo (assunto) precisa ser continuado. Isso pode gerar certa imprevisibilidade no discurso. Às vezes, o assunto toma rumos que fica difícil de se prever. Para Fávero, Andrade, Aquino (2012, p. 21),

"o texto falado deixa entrever
plenamente seu processo de
organização, tornando-se possível
perceber sua estrutura, bem como
suas estratégias organizacionais.
Dessa forma, observam-se nessa
modalidade de textos muitos cortes,
$\begin{aligned} & \text { interrupções, retomadas, } \\ & \text { sobreposições etc." }\end{aligned}$

Ao se transcrever um texto oral para o escrito, muitas de suas especificidades podem se perder. É o caso, por exemplo, de gestos, olhares, ênfases em certas palavras que podem fazer sentido e colaborar para a coesão e coerência de um assunto. De acordo com Fávero (2012, p.34),

\begin{abstract}
"o texto conversacional é coerente: o problema é que como ele obedece a processos de ordem cognitiva, muitas vezes, se torna difícil detectar marcas linguísticas e discursivas dessa coerência, pois ela geralmente não se dá com base nessas marcas, mas na relação entre os referentes; daí a importância da noção de controle referencial estabelecida com base na organização tópica, e é por isso que o estudo do desenvolvimento dos tópicos vem adquirindo cada vez mais ênfase, possibilitando análises discursivas que envolvem maior número de fatores."
\end{abstract}

A questão da referenciação (como por exemplo,o uso de pronomes e advérbios orienta a progressão discursiva de um texto e nos dá a noção sobre o sujeito ou objeto sobre o qual se fala, o tempo em que ocorre a ação e o espaço) é muito importante num texto já que é por meio dela que podemos entender a sequência textual. Ao se transcrever um texto oral para o escrito, alguns desses elementos citados anteriormente, como por exemplo, o olhar, o gesto e até mesmo a referenciação podem ser perdidos, prejudicando a coerência e a coesão dotexto.

\section{O discurso político oral}

O homem é um ser que fala e isso o torna um ser social; a partir de uma conversa, instaura-se sua relação com o mundo, com as pessoas, ou seja, a oralidade faz parte do cotidiano humano. Segundo Marcuschi (2001, p. 25), oralidade é:

Uma prática social interativa para fins comunicativos, que se apresenta sob variadas formas ou gêneros textuais fundados na realidade sonora; ela vai desde uma realização mais informal a mais formal nos mais variados contextos de uso. Muitos apontam a língua falada como nãoplanejada, ao contrário da escrita.

O fato de falarmos tão rapidamente quanto pensamos gera uma discussão em torno da questão do planejamento. Koch (apud PRETI, 2002, p. 51) diz que a conversação natural face a face“é relativamente planejável de antemão, o que decorre, justamente, de sua natureza altamente interacional; assim, ela é localmente planejada, isto é, planejada e replanejada a cada novo lance do jogo". A conversação pode sertanto face a face, quando 
encontramos alguém na rua, por exemplo, como pode ser por telefone, por mensagens instantâneas, etc. Em qualquer uma dessas situações, há um planejamento afinal, precisamos disso para dar continuidade ao assunto e não fugir dele. Caso isto não aconteça, corre-se o risco de não haver êxito no discurso. É preciso que o falante conheça seu interlocutor para que planeje seu discurso de acordo com sua plateia.

Um discurso coerente e bem planejado pode persuadir seu interlocutor e colocá-lo numa posição de sujeito dominado. De acordo com Charaudeau (2013, p. 17), "pode-se dizer que todo ato de linguagem está ligado à ação mediante as relações de força que os sujeitos mantêm entre si, relações de força que constroem simultaneamente $o$ vínculo social". Espera-se que um político convença seus interlocutores. É a sua face que está em jogo. Sua imagem não é construída apenas no discurso, sua ação deve estar atrelada a ele, mas este é imprescindível para que se faça política e o político não caia em descrédito. É por meio de seu discurso que o político abre umespaço depersuasão "no qual a instância política, jogando com argumentos da razão e da paixão, tenta fazer a instância cidadã aderir a sua ação" (CHARAUDEAU, 2013, p. 19). Espaço de persuasão seria o lugar social que no caso o político ocupa e o permitepersuadir o interlocutor a aceitar sua proposta. Charaudeau (2013, p. 21) afirma ainda que:
O governo da palavra não é tudo na política, mas a política não pode agir sem a palavra: a palavra intervém no espaço de discussão para que sejam definidos o ideal dos fins e os meios da ação política; a palavra intervém no espaço de ação para que sejam organizadas e coordenadas a distribuição das tarefas e a promulgação de leis, regras e decisões de todas as ordens; a palavra intervém no espaço de persuasão para que a instância política possa convencer a instância cidadã dos fundamentos de seu programa e das decisões que ela toma ao gerir os conflitos de opinião em seu proveito.

A imagem de um político está atrelada tanto à sua ação quanto ao seu discurso. E essa imagem não é só a que ele tem de si próprio, mas a que os outros têm dele também. Ele precisa fazer algo para ser aceito pela sociedade para que essa o reconheça como alguém que os representa. Ele precisa ter consciência do seu ethos, da imagem que ele tem de si e da imagem que fazem dele. , Charaudeau (2013, p. 115)concebe a ideia de que:

$\mathrm{O}$ ethos, enquanto imagem que se liga àquele que fala, não é uma propriedade exclusiva dele; ele é antes de tudo a imagem de que se transveste o interlocutor a partir do que diz, ou seja, a imagem que se cria através do discurso é forte e determinante para a construção de uma imagem social política confiável e bem aceita pela sociedade.

Por isso, a importância da preservação de um discurso político diante de seus interlocutores. Uma imagem positiva pode 
persuadir o interlocutor a aceitar as ideias propostas pelo político.

\section{Análise do corpus: $O$ discurso de Dilma em Bruxelas}

Os trechos do discurso oral de Dilma em Bruxelas que analisaremos evidenciacomo a falta de coerência e coesão pode comprometer a imagem de um político. Ao retextualizá-los, temos:

(...) A zona franca de Manaus... ela: está numa região ... ela é o centro dela porque ela é capital da Amazônia... o Amazonas que é o estado tem 1.570.746 é... é... quilômetros quadrados... então... é uma região extremamente grande com uma população rarefeita mas significativa se a gente somar Amazonas aos três estados menores da região: nós chegamos a uma população de seis milhões de habitantes essa população ela precisa da zona franca de Manaus porque na zona franca de Manaus se produz não é uma zona de exportação é uma zona para a produçãopara o Brasil e nela é... gera-se emprego e renda para essa população na área de indústria eletroeletrônica: portanto ela tem um objetivo ela evita o desmatamento: que é altamente lucrativo: derrubar árvore/árvores plantadas pela natureza: é altamente lucrativo... é muito melhor para o mundo e para o Brasil a área de produção de eletroeletrônicos e ao mesmo tempo ela/elaevita também a emissão de gases de efeito estufa por ser uma produção é... menos... ofensiva ao meio ambiente: eu quero destacar que além de ser uma grande reg/ é a maior floresta amazôni/é... tropical do mundo a floresta amazônica mas além disso ali tem a maior... a maior... volume de água doce do planeta e também é uma região extremamente atrativa do ponto(m)do ponto de vista mineral por isso preservá-la implica necessariamente isso que: o governo brasileiro gasta ali o governo brasileiro gasta um recurso bastante significativo ali seja porque olhamos a importância do que tiramos da Rio mais Vinte de que era possível incluir conservar e proteger.

No fragmento a seguir, percebe-se que o tópico discursivo é a zona franca de Manaus e o que ela oferece em termos de benefícios para a região. Observe:

(...) A zona franca de Manaus... ela: está numa região ... ela é o centro dela porque ela é capital da Amazônia... o Amazonas que é o estado tem 1.570 .746 é... é... quilômetros quadrados...(...)

Nesse excerto, percebemos que a repetição do pronome pessoalreto (ela) é recorrente. Apesar de sabermos da importância do uso de referentes em nossos textos e como eles colaboram para o êxito do discurso, não foi o que aconteceu no trecho do discurso da presidenta Dilma que estamos analisando. A alta incidência de repetições de um mesmo termo, no caso o pronome pessoal reto ( $3^{\text {a }}$ pessoa do singular)ela, parece mostrar certa insegurança na abordagem do assunto e causa confusão no entendimento do discurso. Quando a presidenta afirma: (...)A zona franca de Manaus... ela: está numa região ... ela é o centro dela porqueela é a capital da Amazônia(...),a primeira vez que ela usa o referente ela, entende-se que se fala sobre a zona franca de Manaus, entretanto quando ela diz: ela é o centro dela, não se sabe se o que ela quer dizer é que a zona franca de Manaus é o centro dela própria, se está no centro da região amazônica ou se a zona franca de Manaus é a capital do Amazonas, e que no caso ela parece se confundir dizendo que a zona franca de Manaus é a capital da floresta amazônica. Como se pode perceber, há um estranhamento, ou seja, o uso excessivo de pronomes prejudicou o entendimento do interlocutor. Um discurso mal planejado pode 
causar desentendimento, prejudicando assim, a mensagem emitida por parte do locutor. É preciso que cada trecho do discurso esteja encadeado adequadamente para que haja a coerência, isto é, o uso de elementos coesivos como pronomes, por exemplo, é relevante . Nesse caso não foi o que ocorreu, já que esses elementos coesivos não puderam contribuir para a existência da coerência em sua fala.

Em outro fragmento, ocorre a interrupção de ideias que também fragilizamo entendimento do discurso:

(...)... o Amazonas que é o estado tem 1.570.746 é... é... quilômetros quadrados... então... é uma região extremamente grande com uma população rarefeita mas significativa: se a gente somar o Amazonas aos três estados menores da região: nós chegamos a uma população de seis milhões de habitantes essapopulaçãoela precisa da zona franca deManaus porque nazona franca de Manaus se produz não é uma zona de exportação é uma zona para a produçãopara o Brasil e nela é... gera-se emprego e renda para essa população na área de indústria eletroeletrônica: (...).

Já nesse excerto, quando a presidenta diz: (...... o Amazonas que é o estado tem 1.570 .746 é... é... quilômetros quadrados...(...), o emprego do aposto não prejudica o entendimento da ideia, mas poderia ter sido usado de uma outra forma: o estado do Amazonas tem 1.570.746 quilômetros quadrados. O texto ficaria mais claro, objetivo e conciso e não haveria a necessidade de se explicar que o Amazonas é o estado.

Emum outro trecho, ocorre um problema crucial: a ruptura de ideias. Vejamos: essapopulaçãoela precisa da zona franca deManaus porque nazona franca de Manaus se produz não é uma zona de exportação é uma zona para a produçãopara o Brasil e nela é... se gera emprego e renda para essa população na área deindústria eletroeletrônica:(...)

Dilma inicia seu discurso dizendo que a população local precisa da zona franca de Manaus; logo em seguida interrompe a ideia para explicar que a zona franca de Manaus não é uma zona de exportação, para só depoisreiterar a ideia inicial, por meio do referente nela, afirmando que a zona franca de Manaus gera emprego e renda para a população. Numa conversação informal face a face, o problema não chamaria tanto a atenção, mas em se tratando de um discurso internacional, coberto por toda a mídia, o discurso parece ter tomado uma amplitude maior, já que políticos de renome e internacionalmente conhecidos estavam presentes no evento, gerando críticas.A própria revista Veja de 26/02/14 publicou uma crítica sobre esse discurso da presidenta, salientando a falta de coesão e coerência em seu discurso público.

Em mais um fragmento existe um problema coesivo relevante que ela mesma corrige, realizando uma estratégia metadiscursiva:

na zona franca de Manaus se gera emprego e renda para essa população na área de indústria eletroeletrônica: portanto ela tem um objetivo ela evita o desmatamento: queé altamente lucrativo: derrubar árvore/árvores plantadas pela natureza: é altamentelucrativo... 
A presidenta afirma num primeiro momento que a zona franca de Manaus evita o desmatamento e que ele é altamente lucrativo. Em seguida ela mesma percebe que sua construção frasal ficou estranha e reitera dizendo que derrubar árvores plantadas pela natureza é altamente lucrativo. Aqui ela não se refere apenas ao fato de derrubar as árvores e, sim, derrubá-las e comercializá-las, isso é lucrativo. Porém a construção derrubar árvores plantadaspela natureza não soou bem e dizer queo objetivo da zona franca de Manaus é evitar o desmatamento também não é lógico . Outro problema recorrente na fala da presidenta é a organização das orações; todo esse problema foi gerado devido à colocação de uma oração subordinada no meio do período - queé altamente lucrativoprejudicando a coesão.

Num próximotrecho, ela comete outro erro ao quase afirmar que a floresta amazônica é a maior do mundo (existe apenas uma), percebendo o deslize, corrige-o rapidamente dizendo que a floresta amazônica é a maior floresta tropical do mundo:

...é a maior floresta amazôni/é... tropical do mundoafloresta amazônica

Ainda nesse mesmo trecho, a presidenta realiza um truncamento: quando ela percebe que o que ia dizer não faz sentido, ela rapidamente interrompe o que estava dizendo para falar algo mais adequado, ou seja, ela faz uso de uma autocorreção para a preservação de sua imagem.
Nesse mesmo excerto, a presidentacontinua“(...) mas além disso ali tem amaior... a maior... volume de água doce do planeta (...)".Ao elaborar seu discurso, ela não faz a correção do gênero, já que o vocábulo volume é masculino. Nesse caso, houve um problema em termos microestruturais, que na verdade não afetou o entendimento do fragmento, mas que poderia ter sido revisto.

Já no último trecho de seu discurso, a presidenta faz uso de catáfora para anunciar algo que ainda será dito e nesse caso, é preciso se ater ao que vem depois do pronome demonstrativoisso, e logo após faz uso do advérbio ali para se referir à zona franca de Manaus, como se observa em:

(...) também é uma região extremamente atrativa do ponto $(\mathrm{m})$ do ponto de vista mineral por isso preservá-la implica necessariamente isso que: o governo brasileiro gastaali o governo brasileiro gasta um recurso bastante significativo ali seja porque olhamos a importância do que tiramos da Rio+20 de que era possível incluir conservare proteger.

Neste último fragmento, mesmo fazendo uso de referentes importantes como, por exemplo, o pronome demonstrativo isso e o advérbio ali, as escolhas lexicais parecem não surtir muito efeito no que diz respeito à coesão e coerência. A presidenta inicia seu texto falando sobre a importância da preservação da região do ponto de vista mineral, diz que essa preservação implica um alto recurso que o governo gasta ali e termina dizendo que retiraram essa ideia da Rio +20 .
A oração seja porque olhamos a 
importância do que tiramos da Rio+20 de que era possível incluir conservare proteger, causa estranhamento pela falta de coesão causada pelo emprego da expressão seja porque, já que para fazer uso dessa expressão, ela deveria ter empregado uma outra oração de mesmo valor.

\section{Considerações finais}

O papel dos participantes do discurso é definido conforme a situação. Podemos ser mais informais em determinadas situações, como numa conversa por telefone ou numa conversa com amigos, por exemplo; entretanto há situações que exigem que sejamos mais formais em termos de linguagem e o discurso político é um deles. Dependendo do lugar de onde o político esteja discursando, é necessário um pouco mais de formalidade na situação, o que não quer dizer que não possamos utilizar de recursos próprios da fala como repetições e truncamentos, mas é necessário que se faça um discurso apropriado à situação. Num encontro internacional, por exemplo, é preciso observar algumas regras contratuais da conversação que garantam o entendimento do assunto por parte do interlocutor. É necessário que o tópico discursivo esteja claro e que a condução deste seja feita de maneira objetiva e coerente.

Em ano eleitoral é comum que todas as atenções se voltem para o discurso político. O que nos chamou a atenção foram os vários problemas apresentados no discurso da presidenta Dilma em Bruxelas, problemas esses que colocam seu poder de persuasão em risco. Isso, muitas das vezes,torna-se motivo de piadas e críticas, o que não é bom para a imagem de uma representante de um país. Os trechos do discursofeito em Bruxelas, não são diferentes: muitos são os problemas que percebemos, prejudicando assim, o seu entendimento. Enquanto o discurso era lido, tudo corria bem, mas quando a presidenta deixa suas anotações para falar por si, seu discurso causa mal-entendidos por apresentar problemas de coerência e coesão causados por excesso de referenciação, emprego de aposto desnecessário, interrupções, entre outros.

\section{Referências}

BENTES, Ana Cristina. Linguística Textual. In: BENTES, Ana Cristina; MUSSALIM. Fernanda. Introdução à Linguística: domínios e fronteiras, vol. 1. São Paulo: Cortez, 2012.

CHARAUDEAU, Patrick. Discurso político. Trad. Dilson Ferreira da Cruz e Fabiana Komesu. São Paulo: Contexto, 2013.

FÁVERO, LeonorLopes ; ANDRADE, Maria Lúcia C. V. O. ; AQUINO, Zilda G. O. Oralidade e escrita. 8. ed. São Paulo: Cortez, 2012. 
KOCH, Ingedore G. Villaça. Introdução à linguística textual: trajetória e grandes temas. São Paulo: Martins Fontes, 2004.

. O texto e a construção dos sentidos. São Paulo: Contexto, 1997.

MARCUSCHI, Luiz Antônio. Da fala para a escrita: atividades de retextualização. São Paulo: Cortez, 2001.

PRETI, Dino. (Org.). Interação na fala e na escrita. São Paulo: Humanitas, 2002.

RODRIGUES, C. Souza. Língua falada e língua escrita. In: PRETTI, Dino. (Org.). Análise de textos orais. $6^{\text {a }}$ ed. São Paulo: Humanitas, 2003. 